12,18

\title{
Туннельный ток между структурными элементами тонких графен/нанотрубных пленок
}

\author{
() О.Е. Глухова, М.М. Слепченков, П.А. Колесниченко
}

Саратовский национальный исследовательский государственный университет им. Н.Г. Чернышевского, Саратов, Россия

E-mail: glukhovaoe@info.sgu.ru

Поступила в Редакцию 26 июля 2021 г.

В окончательной редакции 26 июля 2021 г.

Принята к публикации 4 августа 2021 г.

На основе построенных атомистических моделей графен/нанотрубных пленок с различным количеством нанотрубок в суперъячейках проведены in silico исследования закономерностей неравномерного распределения плотности, обуславливающие наличие островковой структуры у подобных пленок. В результате квантового молекулярно-динамического моделирования установлено, что тонкие трубки субнанометрового диаметра обволакиваются графеновыми листами, что делает их энергетически устойчивыми и стабильными. Также исследованы туннельные контакты между отдельными фрагментами пленок, не связанными ковалентно, в частности между листами графена с различной топологией контактирующих краев zigzag и armchair в зависимости от расстояния между ними, и между трубок различных хиральностей, включая $(6,3),(4,4)$, $(6,5),(12,6)$ и $(16,0)$.

Обнаружено, что туннельные контакты трубок с полупроводниковым типом проводимости характеризуются наличием у ВАХ интервалов напряжения с отрицательным дифференциальным сопротивлением. Подобных интервалов напряжения не наблюдается совсем у трубок с металлическим характером проводимости. Полученные новые знания важны для оценок электропроводности подобных пленок, две трети которых составляют полупроводниковые трубки.

Ключевые слова: графен, нанотрубки, туннельные контакты.

DOI: 10.21883 /FTT.2021.12.51684.180

\section{1. Введение}

Двумерные материалы перспективны для использования в атомарно-тонкой электронике, оптоэлектронике и гибкой электронике из-за их контролируемых электронных свойств, оптической прозрачности, легкости переноса на подложку и совместимости с современными технологиями для интегральных схем [1]. Однако, подобными свойствами обладают и тонкие пленки с разветвленной структурой, созданные на основе одностенных углеродных нанотрубок (ОУНТ) и графеновых чешуек/нанолент [2]. Управление топологией пленок осуществляется лазерным направленным воздействием, с одной стороны, а с другой - синтез графена с молекулярно ровными краями был достигнут уже десятилетие назад [3-7]. Эффект краевых состояний графеновых нанолент уже исследован для применений в планарной графеновой электронике [8]. Показано, что планарная конфигурация графена открывает широкие возможности для построения на его базе туннельного полевого транзистора [9]. Применениям ОУНТ посвящено много работ. Как неоднократно показано, ОУНТ могут использоваться в полевых транзисторах [10], в нанохроматографии [11], различных сенсорах [12]. При этом нанотрубки образуют сетки с разветвленной структурой. Современный подход к синтезу сеток на основе ОУНТ и графеновых фрагментов с помощью лазерного облучения, позволяет получить высокопрочные и высокопроводящие тонкие пленки, применяемые не только в электронике, но и в биомедицине [2]. Одним из важных вопросов применения таких сеток в полевых транзисторах является влияние сопротивления туннельного перехода между структурными элементами сетки и контактными электродами на характеристики транзисторов. Однако, если подобные сетки и не применяются в транзисторах, то всегда остается актуальной проблема влияния туннельных переходов, связывающих отельные фрагментарные структурные элементы друг с другом, на электропроводность всей наноструктурной системы [13,14]. В работе [14], посвященной туннельным переходам между ОУНТ, замечено, что для снижения негативного влияния туннельных переходов необходимо повышать плотность пленок из нанотрубок, которая, как известно, является неоднородной. Таким образом, надо отметить, что при синтезе пленок из ОУНТ и графеновых фрагментов плотность пленки приобретает так называемый островковый характер, когда в структуре пленки имеются явно выраженные локальные области с повышенной плотностью.

Данная работа посвящена in silico исследованию закономерностей туннельного тока между графеновыми листами и хиральными ОУНТ, образующими тонкую пленку с островковой структурой. Были рассмотрены трубки различной хиральности, в частности, тонкие 
трубки $(6,3)$ и $(4,4)$, а также наиболее часто синтезируемые $(6,5),(12,6)$ и $(16,0)$.

\section{2. Математическое моделирование: подходы и методы}

Для расчетов туннельных контактов были использованы метод функций Грина и приближение сильной связи. В рамках данного формализма туннельный ток описывается выражением [15]:

$$
\begin{aligned}
I= & \frac{e}{h} \int_{-\infty}^{\infty} \operatorname{Tr}\left[A_{L}\left(1-t^{\dagger} g_{R}^{-} t g_{L}^{-}\right)^{-1} t^{\dagger} A_{R} t\left(1-g_{L}^{+} t^{\dagger} g_{R}^{+} t\right)^{-1}\right] \\
& \times\left[f_{L}-f_{R}\right] d \varepsilon
\end{aligned}
$$

где $g_{R, L}^{+}=\left[\left(\varepsilon+i O^{+}\right) 1-H_{R, L}\right]^{-1}-$ запаздывающая функция Грина для краевых атомов правого (левого) контактов, $g_{R, L}^{-}=\left(g_{R, L}^{+}\right)^{\dagger}, A_{R, L}=i\left(g_{R, L}^{+}-g_{R, L}^{-}\right)-$спектральная плотность электронов, $t$ - матрица взаимодействия атомов левого и правого контактов, $f_{L}=f(\varepsilon-e V / 2), \quad f_{R}=f(\varepsilon+e V / 2), \quad f(\varepsilon)=$ $=\left[1+\exp \left(\varepsilon / k_{\mathrm{B}} T\right)\right]^{-1}-$ функция Ферми-Дирака.

Описанный подход реализован в программе Mizar, разработанной при участии авторов данной работы [16]. Оба контактирующих объекта подвержены влиянию общего затвора. Реакция системы на напряжение затвора была учтена обычным образом: $H_{R, L}(\varepsilon) \rightarrow H_{R, L}\left(\varepsilon+V_{g}\right)$. Отметим, вторые слагаемые в круглых скобках выражения (1) учитывают влияние одного контакта на электронные состояния другого. Ранее в работе [17] был применен аппарат функций Грина в сочетании с пи-электронным приближением для исследования туннельных контактов между графеновыми листами с одинаковой топологией краев. Была показана высокая эффективность применяемых подходов. Все расчеты проводятся для $k_{\mathrm{B}} T=0.001 t_{0}$ и при напряжении затвора $V_{g}=0.05 t_{0}$ $\left(t_{0}\right.$ - параметр взаимодействия между соседними атомами [17]).

Построение атомистических моделей графен/нанотрубных пленок осуществлялось с помощью метода функционала плотности в приближении сильной связи с самосогласованием заряда (метод SCC DFTB), а также с применением универсального силового поля (UFF) для учета ван-дер-ваальсового взаимодействия отельных фрагментов пленки. Равновесная конфигурация суперьячеек тонких пленок достигалась минимизацией полной энергии при варьировании всех координат всех атомов суперъячейки пленки с соответствующим заданием периодических граничных условий. Далее, для выявления атомной структуры пленок при нормальных условиях (температуре $300 \mathrm{~K}$ и нормальном давлении) проводилось молекулярно-динамическое моделирование (МДМ) в течение $1 \mathrm{~ns}$ с временным шагом $1 \mathrm{fs}$. При этом с шагом 1 ps фиксировалась полная энергия, кинетическая энергия, объем суперъячейки и другие энергетические и механические параметры. Надо отметить, что в ходе МДМ варьировались не только координаты атомов, но и трансляционные векторы суперьячейки (для выявления их оптимальных значений при нормальных условиях), что и приводило к изменению объема в ходе МДМ. Все упомянутые расчеты осуществлялись с применением программного пакета DFTB + [18]. Этот программный пакет, как и Mizar, зарекомендовали себя как надежные инструменты квантового прогностического моделирования новых свойств наноструктур.

\section{3. Атомистические модели графен/нанотрубных пленок с островковой структурой}

Для построения атомистических моделей графен/ нанотрубных пленок изначально были взяты фрагменты графеновых чешуек разного размера, фрагменты моно-/бислойных графеновых листов и тонкие нанотрубки хиральностью $(4,4)$ и $(6,3)$. Как известно, тонкие трубки самостоятельно не могут существовать из-за энергетической нестабильности, а только в полости внешней трубки или в составе композитных структур. В связи с этим они и были выбраны для данной модели пленки, где трубки как бы обволакиваются графеновыми листами и изолируются от окружения.

На рис. 1, $a$ показана одна из построенных атомистических моделей суперъячейки подобной пленки. Размеры суперьячейки до реализации МДМ (см. п. 2) составили $3.4 \times 4.8 \times 4.0 \mathrm{~nm}$. В одной суперьячейке присутствуют только две трубки $(4,4)$ и $(6,3)$ при количестве атомов 4105 . В ходе МДМ значение полной энергии $E_{\text {tot }}$ менялось во времени (рис. $1, b)$. Можно сказать, что энергия колебалась около среднего значения, которое составило $-3121 \mathrm{eV}$ (получено усреднением за все время, то есть за $1 \mathrm{~ns}$ ). Колебания полной энергии системы вызваны, с одной стороны, тепловой энергией, с другой - процессом оптимизации атомной сетки суперъячейки. Как видно из рис. $1, b$, к концу молекулярнодинамического моделирования, на 850-й пикосекунде колебания энергии наблюдаются около значения ниже среднего значения, что свидетельствует о стабилизации структуры и достижении ею оптимального энергетически выгодного состояния. Действительно, если в первые $400 \mathrm{ps}$ наблюдаются колебания энергии $1-1.5 \%$ около среднего значения, то после 500-й пикосекунды колебания становятся менее $1 \%$, составляя по абсолютной величине $\sim 0.5 \mathrm{ps}$. Аналогичные колебания наблюдаются и для величины объема (см. рис. $1, b)$. В первые 300 ps объем мало меняется, но затем происходит увеличение объема суперъячейки в процессе МДМ, что свидетельствует об увеличении длин векторов трансляций. К концу времени моделирования ситуация стабилизируется, и величина объема меняется около среднего значения в пределах $\pm 0.07 \%$. Среднее значение объема за время МДМ составило $71.528 \mathrm{~nm}^{3}$. Отметим, что 

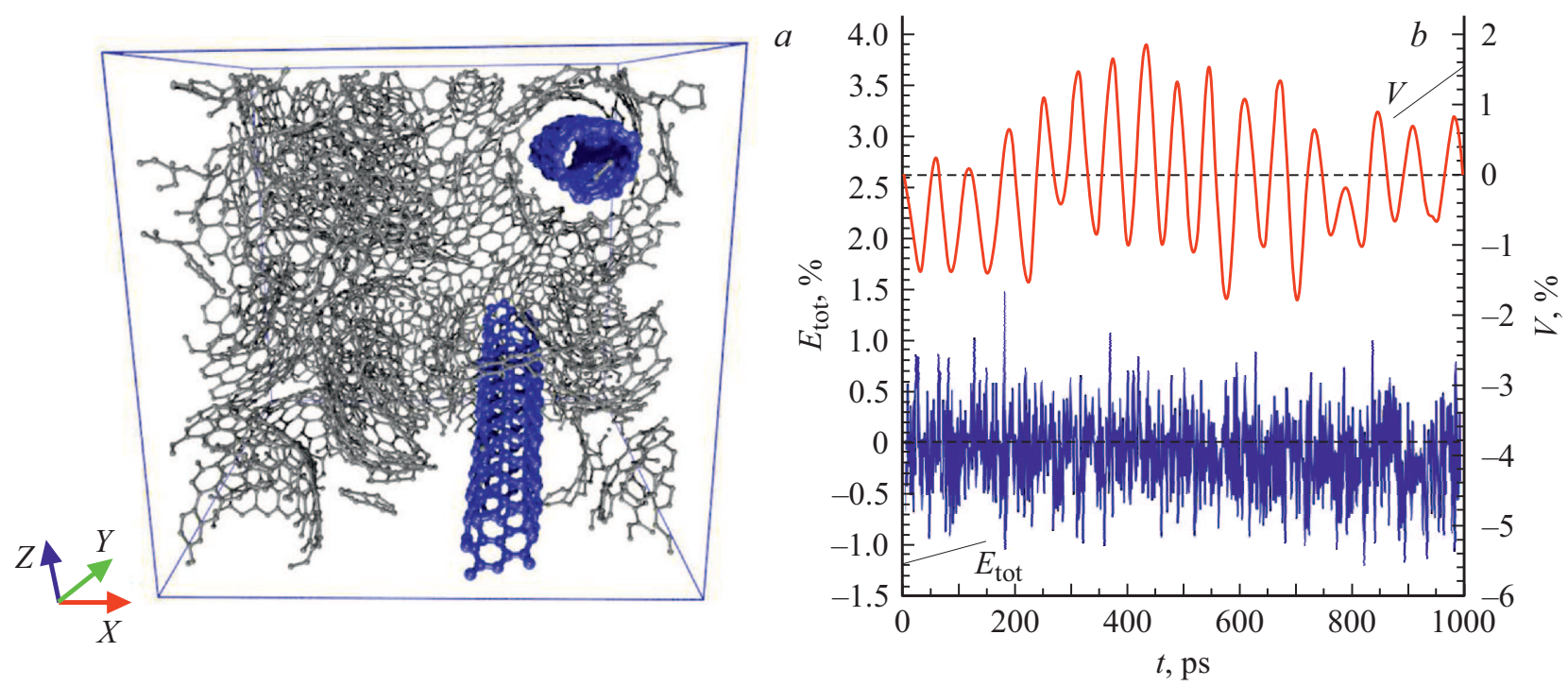

Рис. 1. Первая модель пленки с двумя трубками в ячейке: $(a)$ атомистическая модель суперъячейки; $(b)$ графики изменения полной энергии $E_{\text {tot }}$ и объема $V$.
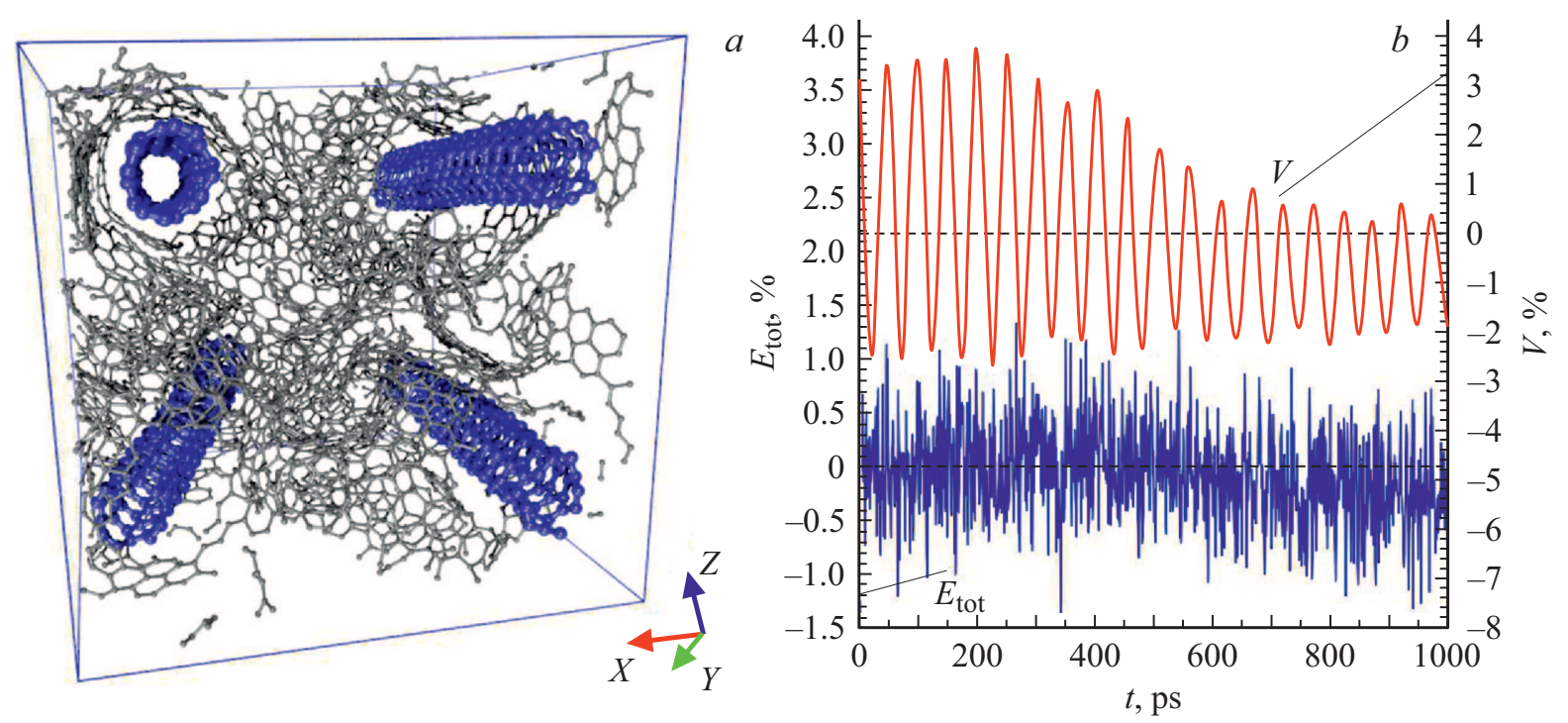

Рис. 2. Вторая модель пленки с четырьмя трубками в ячейке: $(a)$ атомистическая модель суперьячейки; $(b)$ графики изменения полной энергии $E_{\text {tot }}$ и объема $V$.

в ходе МДМ варьировались векторы трансляций (то есть длины суперъячейки) вдоль всех трех осей $X, Y$ и $Z$. Представленная на рис. $1, a$ структура отвечает оптимальной конфигурации суперьячейки с размерами $3.58 \times 5.00 \times 4.00 \mathrm{~nm}$. Из полученной $3 \mathrm{D}$ ячейки можно формировать пленки требуемой толщины. Хорошо видно, что графеновые фрагменты охватывают трубки, заключая их как бы в коконы, что и обеспечивает тонким трубкам энергетическую стабильность. Длина трубки $(4,4)$ по итогам оптимизации ячейки составила $\sim 4.7 \mathrm{~nm}$, а трубки $(6,3)-3.26 \mathrm{~nm}$, что меньше длины периодического ящика по оси $Y$.

Другая модель графен/нанотрубной пленки представлена на рис. 2,a. Ее суперъячейка включает в себя две трубки $(4,4)$ и две трубки $(6,3)$. Методика построения атомистической структуры была той же, что и в предыдущем случае. Размеры этой суперъячейки составляли $4 \times 5 \times 4 \mathrm{~nm}$ до МДМ (см. разд. 2), при этом она включается в себя 4358 атомов. Изменения полной энергии и величины объема ячейки показаны на рис. 2, $b$. Как и в предыдущем варианте модели пленки, полная энергия уменьшается в своих колебаниях около положения равновесия после 700-й пикосекунды. Ее значение становится заметно ниже среднего, равного $-3161 \mathrm{eV}$, а колебания - меньше $0.5 \%$. Такая же ситуация наблюдается и в поведении объема суперъячейки в ходе МДМ. Очень заметны колебания в первые $500-600$ ps с амплитудой - 3\%, и затем происходит 

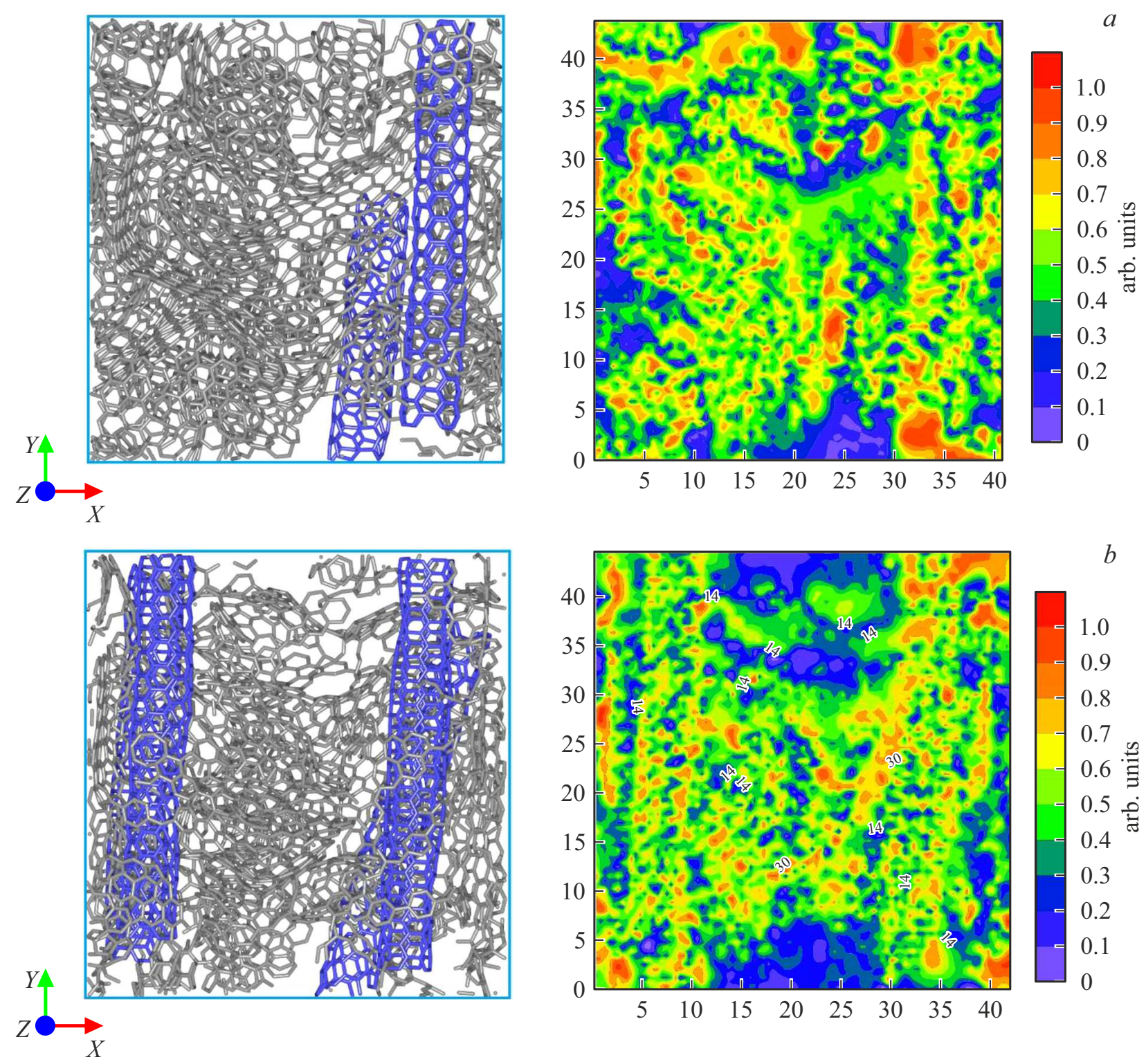

Рис. 3. Распределение плотности островковых структур: (a) для модели с двумя нанотрубками; $(b)$ для модели с четырьмя нанотрубками.

резкое уменьшение колебаний до $1 \%$ с уменьшением объема ниже среднего значения $\left(78.297 \mathrm{~nm}^{3}\right)$ за время МДМ на $0.5 \%$.

Следовательно, структура претерпела перестройку атомной сетки и достигла оптимальной конфигурации. Структура на рис. 2, $a$ отвечает оптимальной конфигурации суперъячейки с размерами $3.73 \times 5.10 \times 4.10 \mathrm{~nm}$. Естественно, с увеличением количества трубок в суперъячейке ее объем увеличился также. Длины всех трубок составляют $\sim 4.5 \pm 0.2 \mathrm{~nm}$.

Анализ распределения плотности суперьячейки показывает ее характерную неоднородность для обеих моделей, то есть островковую структуру, плотность по направлению оси $Z$ заметно меняется при обходе суперъячейки в плоскости $X Y$. На рис. 3 представлены карты распределения плотности графен/нанотрубной пленки. Для удобства показаны суперьячейки с позиции оси $Z$ (сверху) и рядом приведены сами карты. Ось абсцисс карты - это ось $X$ суперьячейки, ось ординат - ось $Y$ (единицы измерения - ангстремы). Единицы измерения плотности - относительные, то есть за „““ принята максимальная величина плотности. Четко выделяются полости суперьячеек и области с максимальной плотностью. Приведенные карты плотности наглядно демонстрируют островковую структуру графен/нанотрубных пленок. Плотность для суперьячейки первой модели составляет $1.143 \mathrm{~g} / \mathrm{sm}^{3}$, плотность для второй модели $1.108 \mathrm{~g} / \mathrm{sm}^{3}$. Действительно, увеличение трубок в ячейке привело к ее разрыхлению, что видно и по рис. $3, b$, где пустоты стали больше по своим размерам. 


\section{4. Туннельные контакты в графен/нанотрубных пленках с островковой структурой}

Как было сказано выше, тонкие графен/нанотрубные пленки имеют очень сложную топологию и развитую структуру, в которой отдельные фрагменты контактируют не только с помощью ковалентных связей, но и ван-дер-ваальсово. При подключении к электродам между фрагментами с ван-дер-ваальсовым типом взаимодействия будет наблюдаться туннельный ток, который определяет во многом электропроводность всей структуры. Для представленных выше моделей один из таких контактов представлен на рис. 4, $a$. Это две суперъячейки первой модели. Между двумя трубками есть ван-дер-ваальсово взаимодействие при расстоянии $\sim 0.3-0.4 \mathrm{~nm}$ (трубки - в верхней части рисунка).

Как было выше сказано (см. разд. 2), в рамках применяемого для исследований туннельных контактов подхода в качестве электродов выступают два полубесконечных фрагмента пленки, не связанных ковалентно. Схематично это можно представить на примере двух трубок следующим образом: две полубесконечные трубки лежат на изолирующей подложке (например, $\mathrm{SiO}_{2}$ ), которая, в свою очередь, располагается на кремниевой подложке, как показано на рис. $4, b$ для двух контактирующих трубок $(12,6)$. На нижний слой подается напряжение затвора $V_{g}$. Сами трубки являются левым (L) и правым (R) электродами. Стрелками показаны направления бесконечного продления трубок. По представленной схеме были рассчитаны вольт-амперные характеристики (BAX) для туннельных контактов трубок $(6,3)$ и $(4,4)$, являющихся фрагментами построенных моделей, а также трубок $(6,5),(12,6)$ и $(16,0)$. Рассчитанные $\mathrm{BAX}$ показаны на рис. $5, b$. Резко выделяются графики для трубок с металлическим характером проводимости $(4,4)$ и $(12,6)$. Для них отсутствует нулевой участок, и ток появляется уже при малых напряжениях. При этом сначала характерен линейный участок роста тока, который сменяется резким увеличением тока, что не наблюдается ни у одной из других рассмотренных трубок. То есть, при определенном напряжении между электродами токоперенос между трубками происходит беспрепятственно и быстро нарастает при дальнейшем увеличении напряжения. График ВАX для контакта $(16,0)-(16,0)$ характеризуется резким пиком увеличения тока с дальнейшей демонстрацией отрицательного дифференциального сопротивления. Последующее нарастание тока наблюдается, но величина тока заметно меньше по сравнению с контактом типа $(12,6)-(12,6)$ и даже $(4,4)-(4,4)$. Такой всплеск величины тока для контакта $(16,0)-(16,0)$ может быть объяснен регулярной (нехиральной) структурой атомной сетки и наибольшим диаметром остова по сравнению со всеми другими исследуемыми трубками. Наибольший диаметр обеспечивает и наибольшее количество контактирующих
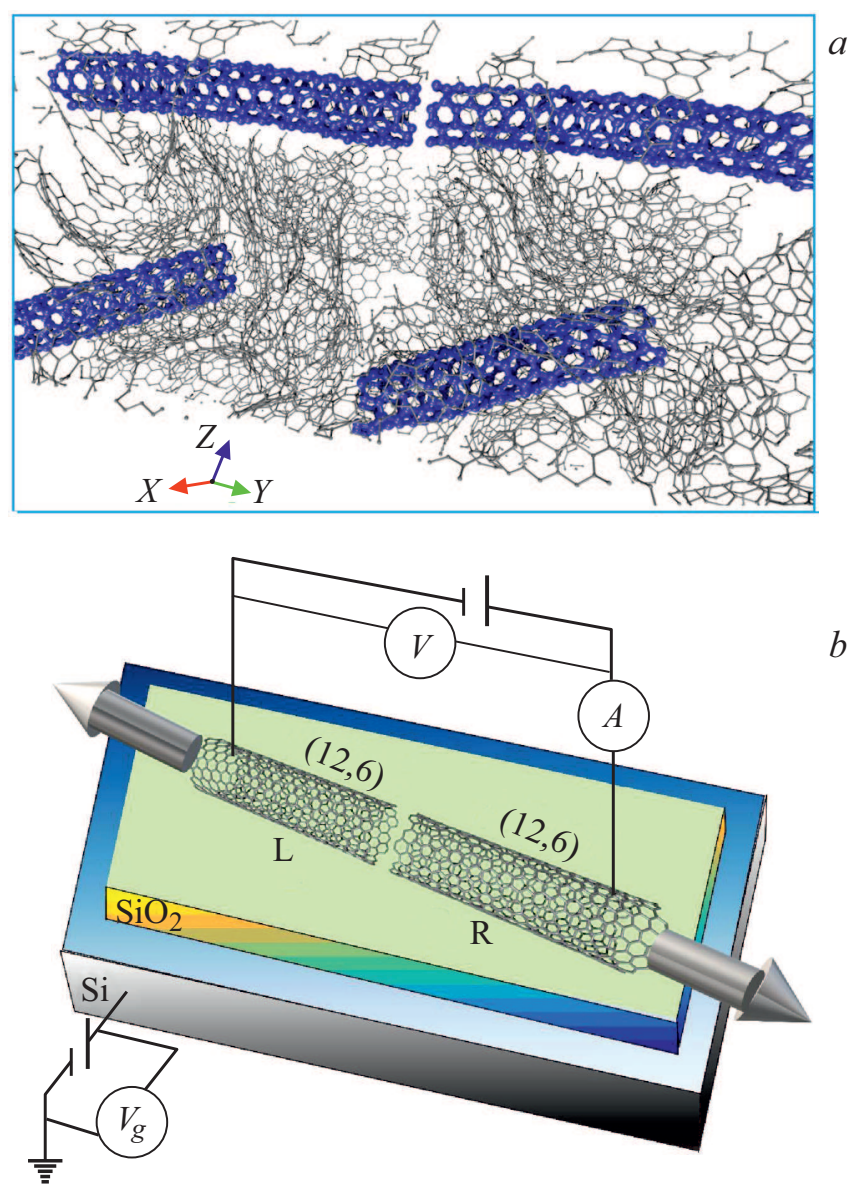

Рис. 4. Туннельный контакт: (a) атомистическая модель туннельного контакта двух нанотрубок в составе пленки; (b) схема подключения трубок для измерения туннельного тока на примере трубок $(12,6)$.

атомов соседствующих трубок. Наихудшие характеристики обнаружили контакты трубок типа $(6,3)-(6,3)$ и $(6,5)-(6,5)$. Оба типа трубок относятся к трубкам субнанометрового диаметра, поэтому в области туннельного контакта находится малое количество контактирующих атомов. Это приводит к медленному росту тока при увеличении напряжения. И, если для контакта $(6,3)-(6,3)$ наблюдается медленное, но устойчивое нарастания тока с напряжением, то для контакта $(6,5)-(6,5)$ рост тока сменяется отрицательным дифференциальным сопротивлением, как и для контакта $(16,0)-(16,0)$. Можно предположить, что такое поведение ВАХ для трубок с полупроводниковым типом проводимости объясняется особенностями их зонной структуры. Без сомнения этот вопрос требует дополнительных значительных исследований. Здесь надо отметить, что расстояние $d$ между трубками было взято различным, но с учетом их хиральности для обеспечения наименьшего расстояния между атомами соседних трубок в области контакта.

Также были проведены расчеты BAX для контакта двух полубесконечных листов графена с разными краями 

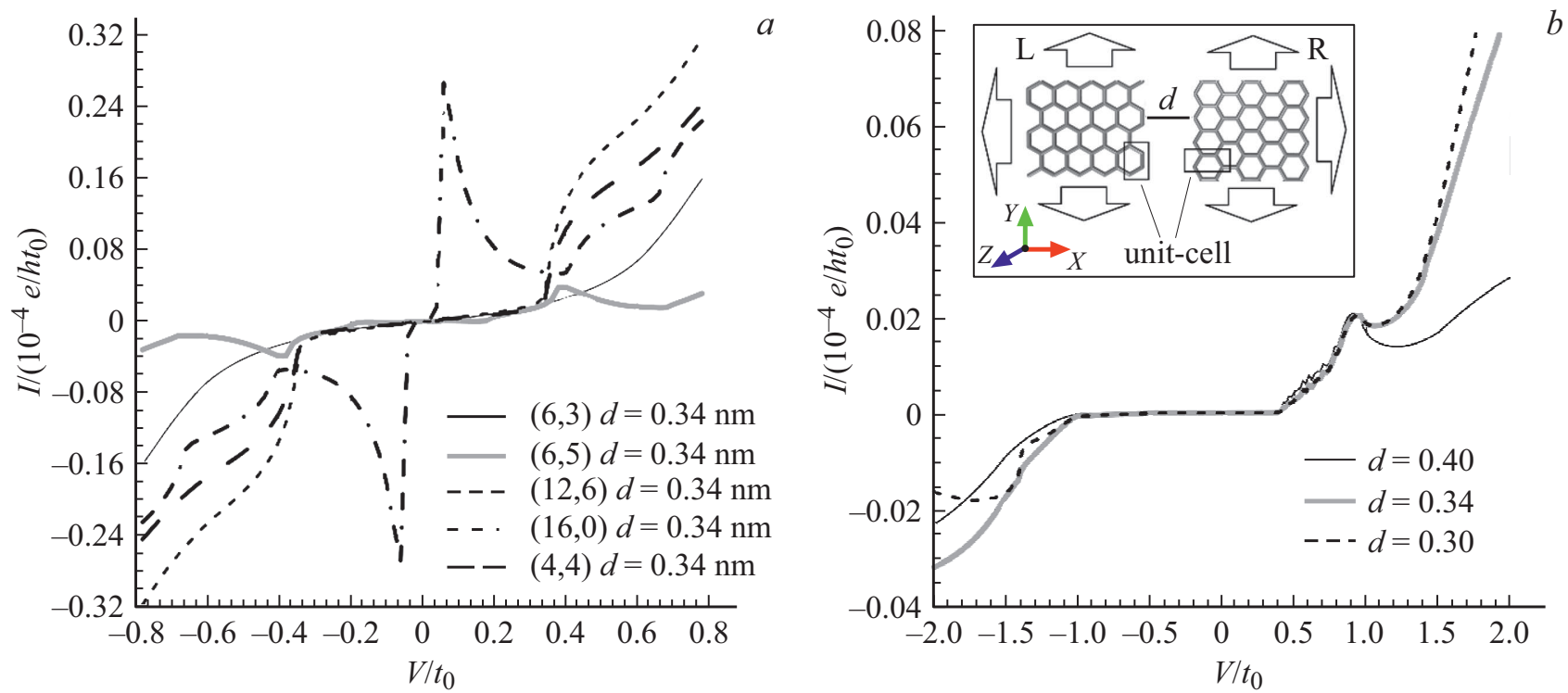

Рис. 5. Вольт-амперные характеристики при напряжении затвора $V_{g}=0.05 t_{0}:(a)$ для туннельных контактов между трубками; (b) для туннельного контакта между графеновыми листами.

zigzag и armchair, как показано на вставке к рис. 5, b. На этом рисунке показаны фрагменты двух графеновых листов, которые являются бесконечными в направлении $Y$ и полубесконечными в направлениях $-X, X$. Элементарные ячейки графеновых листов выделены черными прямоугольниками. Для L-электрода ячейка транслировалась по $Y$ с шагом $2.84 \AA$ и в направлении $-X-$ с шагом $-2.46 \AA$, для R-электрода ячейка транслировалась по $Y$ с шагом $2.46 \AA$ и в направлении $+X-$ с шагом $2.46 \AA$. Видно, что расстояния между атомами соседних графеновых листов меняются на протяжении всего края вдоль оси $Y$. Это приводит к медленному нарастанию туннельного тока и появлению интервала напряжения с отрицательным дифференциальным сопротивлением, который сужается при уменьшении расстояния $d$ между листами графена. Здесь, как и в случае трубок, листы графена являются электродами (см. рис. 4,b). Как и следовало ожидать, кривые семейства ВАХ не являются симметричными.

\section{5. Заключение}

Построены атомистические модели графен/нанотрубных пленок с ковалентными и ван-дер-ваальсовыми связями между фрагментами пленки. Показано, что тонкие трубки $(4,4)$ и $(6,3)$, входящие в состав пленки, покрываются „оболочкой“ из графеновых листов и чешуек, что делает тонкие трубки субнанометрового диаметра энергетически устойчивыми и стабильными. Созданные атомистические модели пленок демонстрируют выраженную островковую структуру, показывая сильную неоднородность распределения плотности, что вызвано присутствием трубок среди графеновых фрагментов, формирующих в основном атомный каркас пленки.
Исследованы in silico туннельные контакты двух листов графена с различной топологией контактирующих краев zigzag и armchair в зависимости от расстояния между ними, а также туннельные контакты трубок различных хиральностей $(6,3)$ и $(4,4)$, являющихся фрагментами построенных моделей, а также трубок $(6,5)$, $(12,6)$ и $(16,0)$. Обнаружено, что именно туннельные контакты трубок с полупроводниковым типом проводимости характеризуются наличием у BAX интервалов напряжения с отрицательным дифференциальным сопротивлением. Это важный момент в характеристике пленки, поскольку, как известно, 2/3 всех синтезируемых трубок в составе пленок - полупроводниковые. Подобных интервалов с отрицательным дифференциальным сопротивлением не наблюдается совсем в случае контактов трубок с металлическим видом проводимости. Полученные новые знания о туннельных контактах фрагментов графен/нанотрубных пленок очень важны для оценок электропроводностей подобных пленок, широко применяемых сейчас в гибкой и высокорастяжимой электронике, а также планарной электронике.

\section{Финансирование работы}

Работа выполнена при поддержке гранта Президента Российской Федерации (проект № MK-2289.2021.1.2) и гранта Российского научного фонда (проект № 21-19-00226).

\section{Конфликт интересов}

Авторы заявляют, что у них нет конфликта интересов. 


\section{Список литературы}

[1] J. Liu, R. Li, H. Li, Y. Li, J. Yi, H. Wang, X. Zhao, P. Liu, J. Guo, L. Liu. New Carbon Mater. 33, 6, 481 (2018).

[2] A.Yu. Gerasimenko, A.V. Kuksin, Y.P. Shaman, E.P. Kitsyuk, Y.O. Fedorova, A.V. Sysa, A.A. Pavlov, O.E. Glukhova. Nanomaterials 11, 8, 187 (2021).

[3] X. Jia, M. Hofmann, V. Meunier, B.G. Sumpter, J. CamposDelgado, J.M. Romo-Herrera, H. Son, Y.P. Hsieh, A. Reina, J. Kong, M. Terrones, M.S. Dresselhaus. Science 323, 5922, 1701 (2009).

[4] C. Jin, H. Lan, L. Peng, K. Suenaga, S. Iijima. Phys. Rev. Lett. 102, 20, 205501 (2009).

[5] A. Chuvilin, J.C. Meyer, G. Algara-Siller, U. Kaiser. New J. Phys. 11, 8, 083019 (2009).

[6] Y. He, H. Dong, T. Li, C. Wang, W. Shao, Y. Zhang, L. Jiang, W. Hu. Appl. Phys. Lett. 97, 13, 133301 (2010).

[7] H.M. Wang, Z. Zheng, Y.Y. Wang, J.J. Qiu, Z.B. Guo, Z.X. Shen, T.Yu. Appl. Phys. Lett. 96, 2, 023106 (2010).

[8] D.A. Ryndyk, J. Bundesmann, M.H. Lin, K. Richter. Phys. Rev. B 86, 19, 195425 (2012).

[9] A.M. Ionescu, H. Riel. Nature 479, 7373, 329 (2011).

[10] A.D. Franklin, Z. Chen. Nature Nanotechnol. 5, 12, 858 (2010).

[11] H. Alhassen, V. Antony, A. Ghanem, M.M.A. Yajadda, Z.J. Han, K.K. Ostrikov. Chirality 26, 11, 683 (2014).

[12] S. Yick, M.M.A. Yajadda, A. Bendavid, Z.J. Han, K.K. Ostrikov. Appl. Phys. Lett. 102, 23, 233111 (2013).

[13] A. Salehi-Khojin, F. Khalili-Araghi, M.A. Kuroda, K.Y. Lin, J.P. Leburton, R.I. Masel. ACS Nano 5, 1, 153 (2011).

[14] M.M. Aghili Yajadda. J. Phys. Chem. C 120, 7, 3646 (2016).

[15] C. Berthod, T. Giamarchi. Phys. Rev. B 84, 15, 155414 (2011).

[16] Mizar [программное обеспечение]. URL: http://nanokvazar.ru, дата обращения: 10.03.2021.

[17] В.Л. Катков, В.А. Осипов. Письма в ЖЭТФ 98, 11, 782 (2013).

[18] B. Hourahine, B. Aradi, V. Blum, F. Bonafé, A. Buccheri, C. Camacho, C. Cevallos, M.Y. Deshaye, T. Dumitrică, A. Dominguez, S. Ehlert, M. Elstner, T. van der Heide, J. Hermann, S. Irle, J.J. Kranz, C. Köhler, T. Kowalczyk, T. Kubař, I.S. Lee, V. Lutsker, R.J. Maurer, S.K. Min, I. Mitchell, C. Negre, T.A. Niehaus, A.M.N. Niklasson, A.J. Page, A. Pecchia, G. Penazzi, M.P. Persson, J. Řezáč, C.G. Sánchez, M. Sternberg, M. Stöhr, F. Stuckenberg, A. Tkatchenko, V.W.Z. Yu, T. Frauenheim. J. Chem. Phys. 152, 12, 124101 (2020).

Редактор Ю.Э. Китаев 